
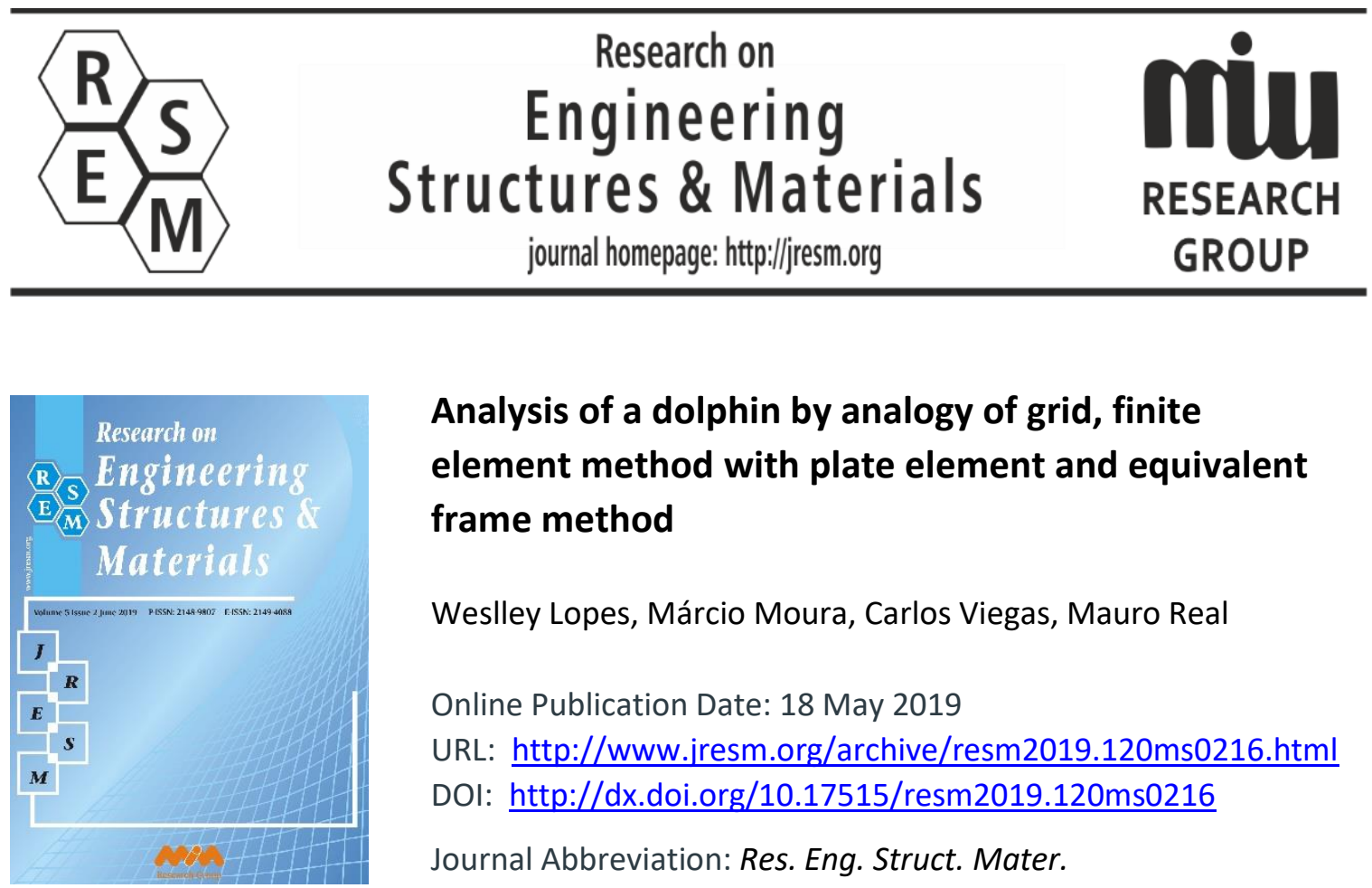

\title{
Analysis of a dolphin by analogy of grid, finite element method with plate element and equivalent frame method
}

Weslley Lopes, Márcio Moura, Carlos Viegas, Mauro Real

Online Publication Date: 18 May 2019

URL: http://www.jresm.org/archive/resm2019.120ms0216.html

DOI: http://dx.doi.org/10.17515/resm2019.120ms0216

Journal Abbreviation: Res. Eng. Struct. Mater.

\section{To cite this article}

Lopes W, Moura M, Viegas C, Real M. Analysis of a dolphin by analogy of grid, finite element method with plate element and equivalent frame method. Res. Eng. Struct. Mater., 2019;

5(4): 427-436.

\section{Disclaimer}

All the opinions and statements expressed in the papers are on the responsibility of author(s) and are not to be regarded as those of the journal of Research on Engineering Structures and Materials (RESM) organization or related parties. The publishers make no warranty, explicit or implied, or make any representation with respect to the contents of any article will be complete or accurate or up to date. The accuracy of any instructions, equations, or other information should be independently verified. The publisher and related parties shall not be liable for any loss, actions, claims, proceedings, demand or costs or damages whatsoever or howsoever caused arising directly or indirectly in connection with use of the information given in the journal or related means.

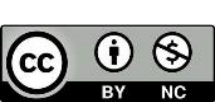

Published articles are freely available to users under the terms of Creative Commons Attribution - NonCommercial 4.0 International Public License, as currently displayed at here (the "CC BY - NC"). 


\title{
Research on Engineering Structures \& Materials
}

journal homepage: http://jresm.org

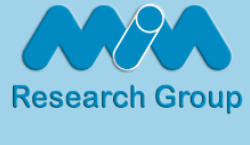

Research Article

\section{Analysis of a dolphin by analogy of grid, finite element method with plate element and equivalent frame method}

\author{
Weslley Lopes ${ }^{*}$, Márcio Mourab ${ }^{b}$ Carlos Viegasc, Mauro Reald \\ Escola de Engenharia, Universidade Federal do Rio Grande, Brazil.
}

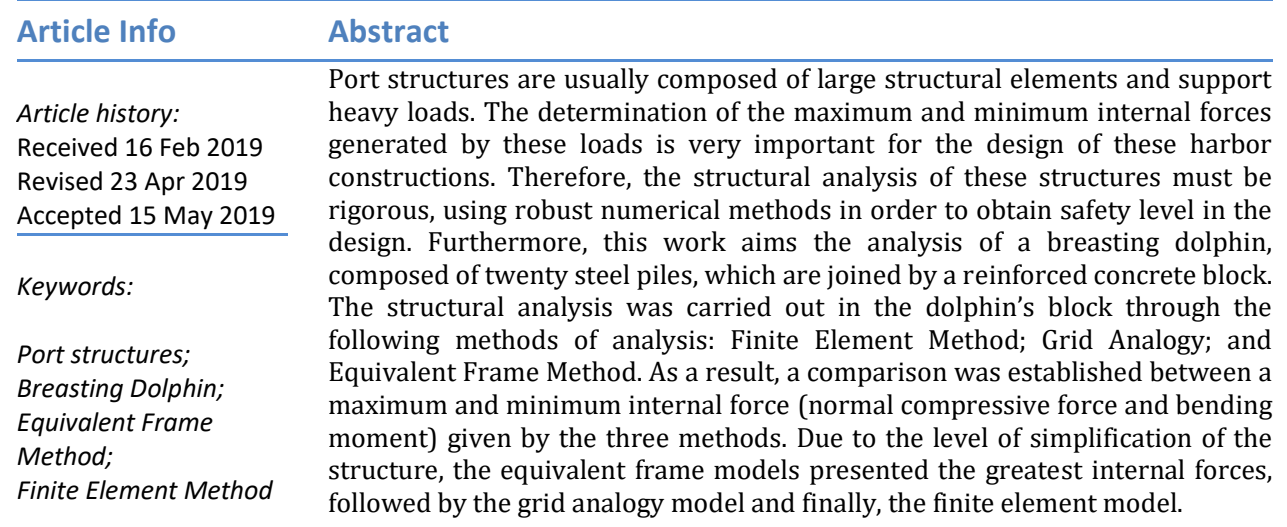

(C) 2019 MIM Research Group. All rights reserved.

\section{Introduction}

The ports have been, over the years, entrance and exit points for goods and people, due to its function of connecting the continent to the sea. In this way, ports have contributed to the stable development of industries and to the development of people's lives by ensuring exchanges of goods with other partners around the world. The port operations involved in these exchanges must ensure the safety of cargo, ships, berthing structure, equipment and especially of the personnel involved in the work. Concomitantly, the berthing structure must satisfy the safety levels for the entire process may occur in a safe manner. [8]

Unlike conventional civil engineering constructions, the berthing structures have some characteristics related to their geometry and loading that highlight them. "In particular, we must emphasize the high values of horizontal loads due to the impacts of ships or traction on the mooring ropes [6]. Also, according to Mason [6], to resist the impact of large ships is feasible the adoption of dolphins, when it is convenient to the build, because these elements are characteristic of discrete structures, which each element do a specific function to ensure the approach, berthing and mooring of ships and vessels.

Due to the importance of these structures, the determination of the maximum and minimum internal forces must be made by methods that guarantee that the peculiarities

\footnotetext{
${ }^{*}$ Corresponding author: weslley.camargo.lopes@hotmail.com

a http://orcid.org/0000-0001-6014-7475; b orcid.org/0000-0003-4134-0848; c orcid.org/0000-0003-

0812-5599: dorcid.org/0000-0003-4916-913

DOI: $\underline{\text { http://dx.doi.org/10.17515/resm2019.120ms0216 }}$

Res. Eng. Struct. Mat. Vol. 5 Iss. 4 (2019) 427-436
} 
of the structure can be considered, about its geometry, behavior of materials, external loads and supports. To achieve this goal, it is necessary introduce robust methods, such as Finite Element Method (FEM), in according with methods simpler, which might offer basis of comparison of results and design tools, such as Grid Analogy and Equivalent Frame Method.

This work aims the determination of the maximum and minimum internal forces in the dolphin block, by the three methods of analysis mentioned before.

\section{Presentation of The Structure}

Dolphins are port structures formed by a monopile or a set of piles joined by a block. Piles can be performed in reinforced concrete or steel and may be constructed vertically aligned or have a slope in relation to the zenith, a feature that helps in absorbing horizontal forces. Its function can be only mooring or berthing, or it can perform both functions: mooring and berthing of vessels.

The dolphin analyzed in this work is displayed in the Fig. 1 and performs the berthing function of ships. Twenty (20) steel piles with cross sections double "I" profile, welded side by side by flanges and a rigid block reinforced concrete that unites the piles, compose the structure. All piles have a slope 1:4 (h:v) and are embedded in a depth of $17.2 \mathrm{~m}$.

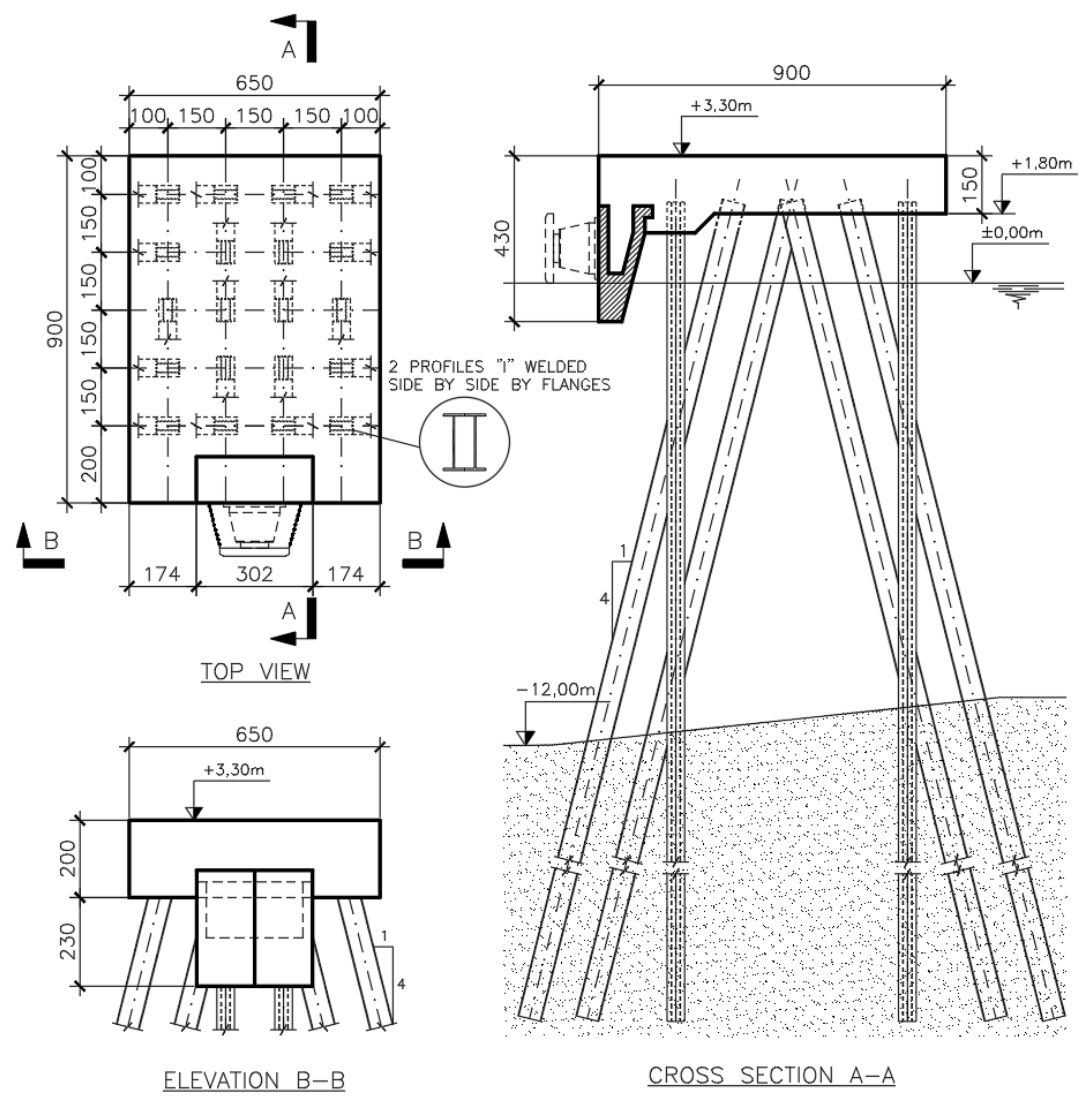


Fig. 1 General scheme of the breasting dolphin. Dimensions in centimeters $(\mathrm{cm})$

The characteristic dimensions of the dolphin that were used for the models are:

- $\quad$ Block dimensions: $9.0 \times 6.5 \mathrm{~m}$;

- $\quad$ Block surface area: $A=58.5 \mathrm{~m}^{2}$;

- Block Height: $\mathrm{h}=1.50 \mathrm{~m}$;

- Pile spacing: $\mathrm{s}=1.50 \mathrm{~m}$

\subsection{Materials and properties}

The dolphin is composed of the materials presented in Table 1.

Table 1. Materials used in the structure

\begin{tabular}{cccccc}
\hline & \multicolumn{5}{c}{ Property of Materials } \\
\cline { 2 - 6 } $\begin{array}{c}\text { Component and } \\
\text { material }\end{array}$ & $\begin{array}{c}\text { Resistance } \\
(\mathrm{MPa})\end{array}$ & $\begin{array}{c}\text { Modulus of } \\
\text { elasticity } \\
(\mathrm{GPa})\end{array}$ & $\begin{array}{c}\text { Poisson } \\
\text { coefficient }\end{array}$ & $\begin{array}{c}\text { Coefficient } \\
\text { of thermal } \\
\text { expansion } \\
\left({ }^{\circ} \mathrm{C}^{-1}\right)\end{array}$ & $\begin{array}{c}\text { Specific } \\
\text { weight } \\
\left(\mathrm{kN} / \mathrm{m}^{3}\right)\end{array}$ \\
\hline $\begin{array}{c}\text { Block: Reinforced } \\
\text { Concrete }\end{array}$ & $f_{c k}=40$ & 30.1 & 0.2 & $1.0 \times 10^{-5}$ & 25.0 \\
$\begin{array}{c}\text { Pile: ASTM A572 } \\
\text { Grade Steel 50 }\end{array}$ & $f_{y}=345$ & 200 & 0.3 & $1.2 \times 10^{-5}$ & 76.5 \\
\hline
\end{tabular}

\subsection{Loads in The Structure}

The loads acting on the structure, which were considered for the construction of the models, are due to the deadweight of the block, live load and berthing load. The first two ones must always be considered in the design and the last one, which was considered only the impact of the ship, are typical of breasting dolphins lied in the sheltered area, where the wave effects are not important. The deadweight of the block (pp) is calculated according to the specific weight of the reinforced concrete $(\gamma c)$ and the dimensions of the block. For live load $(Q s c)$ was adopted a value of $40 \mathrm{kN} / \mathrm{m}^{2}$. The berthing load acts in the position of the dolphin fender in the direction of the largest side of this structure (y direction) with a value of $901 \mathrm{kN}$. This value was taken of table for Super Cone type fenders from the catalog of the Fentek [4], for an impact energy equal to $465 \mathrm{kNm}$, which was calculated according to the PIANC [7].

\section{The Methodology}

In order to determine the internal forces in the dolphin's block, three methods of calculation were chosen for this work: Grid Analogy; Finite Element Method and Equivalent Frame Method. The three models developed were limited to represent the dolphin's block by beams supported on the piles, whose axes are oriented according to the lines of piles of the dolphin. Based on this, the structural analysis was carried out to obtain the normal compression force and bending moments in these beams. All materials used in the models was idealized as elastic-linear. There for, was employed the linear elastic structural analysis.

For the solution of the three-dimensional models by the Grid Analogy and Finite Element Method, was used the software SAP2000. In addition to the SAP2000, the Ftool program was used to solve the two-dimensional models by the Equivalent Frame Method. 


\subsection{Grid Analogy}

According to Araújo [1], the method can be used for analysis of polygonal slabs in different forms and may calculate the efforts on the whole pavement. Thus, this method is based on replacing the dolphin's block with an approximate equivalent grid. According to Araújo [1], this is done by a discretization of the block in two sets of evenly spaced lines.

The block was discretized according to the lines of piles of the dolphin, then was possible to obtain the equivalent grid presented in Fig. 2 . The grid bars are all evenly spaced at 1.50 $\mathrm{m}$ and are positioned belong to the reference plan situated at $1.20 \mathrm{~m}$ below the top of the block, since in this position is lied the top of the piles. The points 1 and 2 in Fig. 2 indicate the position of the fender. Note also in this same figure that the plan containing the block is the $\mathrm{x}-\mathrm{y}$ plane, so the $\mathrm{z}$-axis is orthogonal to this plane, oriented upward.

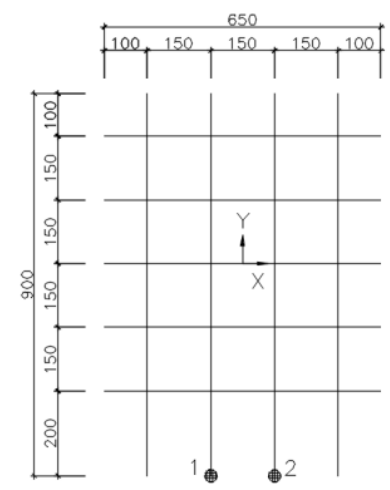

Fig. 2 Equivalent grid. Top view. Dimensions in centimeters (cm)

\subsubsection{Grid model geometry}

The geometry of the three-dimensional model of grid is given according to Fig. 3. In this model are represented the 20 piles and the block of the dolphin, modeled by the equivalent grid. The length of the grid bars is shown in Fig. 2. All piles have a length equal to $17.7 \mathrm{~m}$.

The cross section of the bars representing the piles was modeled as presented in Fig. 4-a. The grid bars have a rectangular cross section with a base of $1.00 \mathrm{~m}$ and a height of 1.50 $\mathrm{m}$, as illustrated in Fig. 4-b.

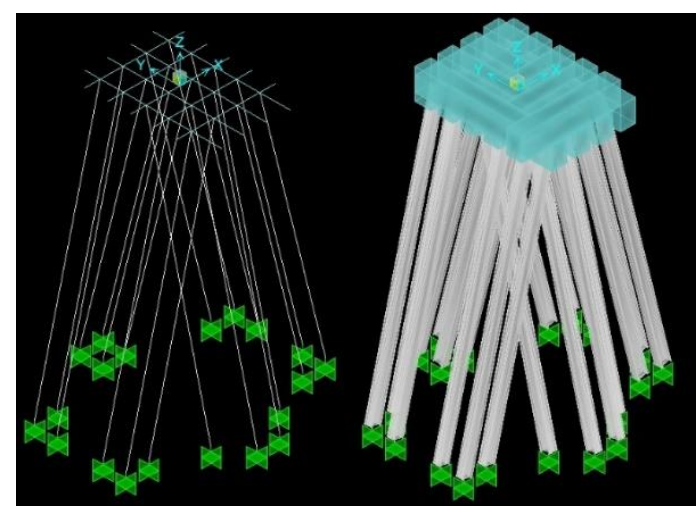


Fig. 3 Three-dimensional model of grids in SAP2000

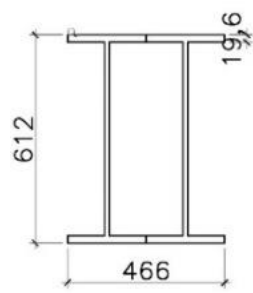

(a)

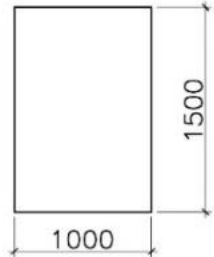

(b)

Fig. 4 (a) Cross section of the piles. (b) Cross section of the grid bars. Dimensions in millimeters $(\mathrm{mm})$

\subsubsection{Loads on the grid model}

Vertical loads resulting from the deadweight $\left(\boldsymbol{Q}_{\boldsymbol{P} P}\right)$ and live loads $\left(\boldsymbol{Q}_{s c}\right)$ were uniformly distributed along the length of the bars of the grid, respectively: $\boldsymbol{Q}_{\boldsymbol{P P}}=\boldsymbol{\gamma}_{\boldsymbol{c}} \cdot \boldsymbol{h} \cdot \boldsymbol{A} / \boldsymbol{l}$ and $\boldsymbol{Q}_{\boldsymbol{s c}}=\boldsymbol{s \boldsymbol { c }} \cdot \boldsymbol{A} / \boldsymbol{l}$, where A=6.5 $\times 9=58.8 \mathrm{~m}^{2}$ is the surface area of the block, $\mathrm{h}=1.50 \mathrm{~m}$ is the height of the block and $l=4 \times 9+5 \times 6.5=68.5 \mathrm{~m}$ is the sum of the lengths of the grid's bars. The berthing load was divided between points 1 and 2 of the equivalent grid in Fig. 2, with a value of $450.5 \mathrm{kN}$ at each point. The moment of the forces is equal to $540.6 \mathrm{kNm}$, which the lever arm of the force is equal to $1.20 \mathrm{~m}$.

\subsection{Finite Element Method with Plate Element}

The Finite Element Method is a numerical method of great application in the Structural Engineering topics, for reticulated structures, structures bi-dimensional and treedimensional.

It uses concepts of "discretization" of the continuum and "interpolation matrix" that provides the displacements at a point inside the element depending on their nodal displacements. The term discretization refers to a model with a number finite of unknowns (nodal displacements in the model nodes) for analysis of continuous in contrast to the analysis with an infinite number of variables as those made by the theory of elasticity that uses continuous functions, that is, with endless unknowns as a solution. [9].

In order to set up the finite element model, plate elements were applied in the grid model for modelling the block of the dolphin. In addition, in order to apply the berthing load, two bars were placed in the position of the fender. The entire mesh of the block was built in order to satisfy the conditions of compatibility, so, the nodes of the bars and plates are coincidental.

\subsubsection{Finite element model geometry}

The geometry of the three-dimensional finite element model is presented in Fig. 5. In this model are represented the 20 piles, the block and the support of the fender with $1.20 \mathrm{~m}$ length. Information about the finite element mesh of the SAP2000 is displayed in Table 2. 
Table 2. Finite element mesh on SAP2000

\begin{tabular}{cccc}
\hline Component & Element & Size & Number of elements \\
& & & \\
\hline Block: Plate & Plate & $50 \times 50 \mathrm{~cm}$ & 234 \\
Block: Bar & Beam & $50 \mathrm{~cm}$ & 137 \\
Support & Beam & $1.20 \mathrm{~m}$ & 2 \\
Pile & Beam & $17.70 \mathrm{~m}$ & 20 \\
\hline
\end{tabular}

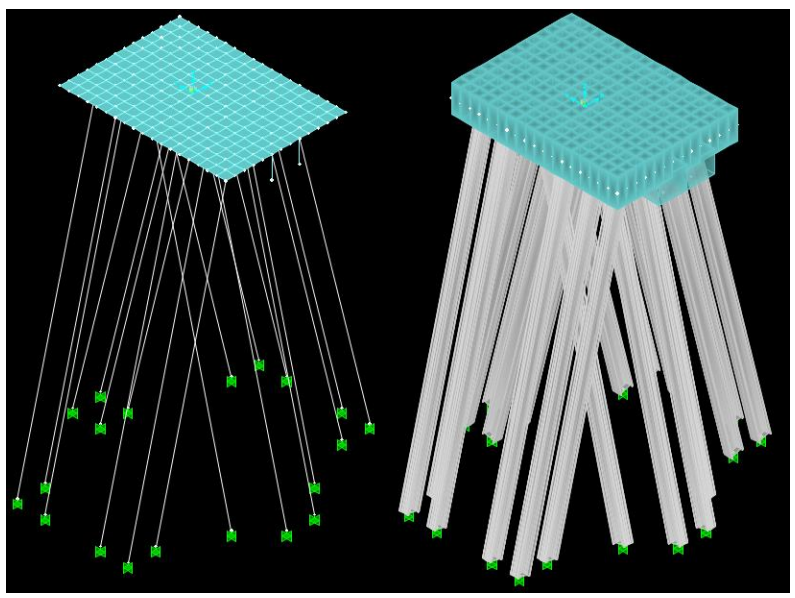

Fig. 5 Three-dimensional model of finite elements in SAP2000

The cross sections of the bars representing the piles and bars of the block are the same as those presented in Fig. 4-a and 4-b, respectively. The board was modeled with a thickness of $1.50 \mathrm{~m}$, equal to the height $\mathrm{h}$ of the block.

\subsubsection{Load on the finite element model}

The deadweight $\left(\boldsymbol{Q}_{\boldsymbol{P} P}\right)$ of the block was applied uniformly distributed loads on the board, with a value equal to $Q_{P P}=\gamma_{c} \cdot \boldsymbol{h}$, where $\gamma_{c}=\mathbf{2 5} \mathbf{k N} / \mathbf{m}^{3}$ is the specific weight of the reinforced concrete and $\mathrm{h}=1.50 \mathrm{~m}$ is the height of the block. Similarly, the live load was applied to the board, with a value equal to $\boldsymbol{Q}_{\boldsymbol{s c}}=\boldsymbol{s c}=\mathbf{4 0} \mathbf{k N} / \boldsymbol{m}^{2}$, as per section 2.2. In this model, the berthing load was again divided (two forces with the equal value of $450.5 \mathrm{kN}$ each) and applied in the bars that represent the element that support the fender, as shown in Fig. 6.

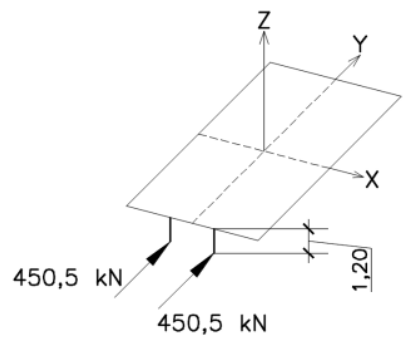

Fig. 6 Berthing load applied to the fender's bars 


\subsection{Equivalent Frame Method}

As said by NBR-6118[2] (Brazilian Norm), the analysis of flat slabs supported on columns arranged in orthogonal queues (with not very different spans and uniformly) can be done through the Equivalent Frame Method. This consists of dividing the slab into two orthogonal series of strips, following the line of columns. The total load should be considered in each frame formed and the internal force resulting from this method are the bending moments in the bars representing the slabs strips.

In this work, the block strips more requested by horizontal load (berthing load) were taken into account. These ones comprise the strips parallel to the direction of the berthing load. In total are four lines of piles (strips) that generate two pairs of plane frames. Each frame was modeled and solutioned by finite element software SAP2000. For the application of the berthing load, a process was used in which employed the Ftool program as a solution tool for the model.

\subsubsection{Loads on the grid model}

The four block strips with their respective widths are displayed in Fig. 7-a, limited by dashed lines. Due to the symmetry of the dolphin, it is possible to note that: F1 = F4 (Frame 01) and F2 = F3 (Frame 02). Thus, the four strips generate two equivalent frames, according to the Fig. 7-b. In these frames, the horizontal bars represent the block strips and the inclined bars with length of $17.7 \mathrm{~m}$ and vertical with length of $17.2 \mathrm{~m}$ represent the piles. The vertical bars of the frames (Fig. 7-b) are the piles with slope out of the plane that contains the frame (see Fig. 1 or Fig. 7-a). It is emphasized that the intersection of the inclined bars with the vertical bars (Fig. 7-b) does not generate a node in the location. Therefore, the program (SAP2000) resolves the structure considering that there is no interaction between these bars.

The cross sections of the bars representing the strips are rectangular, with base equal to the width of the strip (Fig. 7 -a) and height equal to $h=1.50 \mathrm{~m}$. The bars representing the piles have their cross-sectional according to Fig. 4-a.

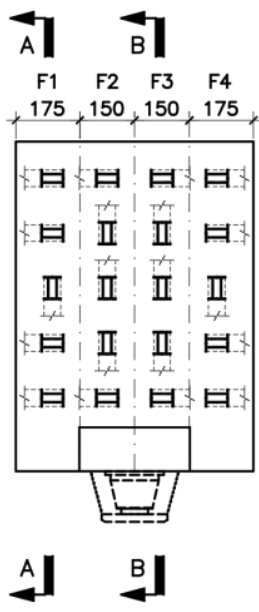

(a)
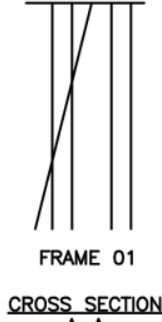

$A-A$

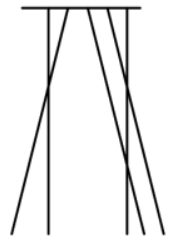

FRAME 02

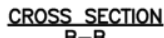

$\mathrm{B}-\mathrm{B}$

(b)

Fig. 7 (a) Block strips. (b) Equivalent frames. Measures in centimeters (cm) 


\subsubsection{Loads on the grid model}

The deadweight $\left(Q_{P P}\right)$ and live load $\left(Q_{S C}\right)$ were applied as uniformly distributed load along the length of the strips: $\boldsymbol{Q}_{\boldsymbol{P P}}=\boldsymbol{\gamma}_{\boldsymbol{c}} \cdot \boldsymbol{h} \cdot \boldsymbol{l}_{\boldsymbol{f}}$ and $\boldsymbol{Q}_{\boldsymbol{s c}}=\boldsymbol{s \boldsymbol { c }} \cdot \boldsymbol{l}_{\boldsymbol{f}}$, respectively, where If is the width of each strip.

For the application of the horizontal load (berthing load), the stiffness method was employed considering the block as a rigid diaphragm. Thereat, each frame receives a portion of the horizontal load proportional to its stiffness to the horizontal translation.

This process was done as follows: (a) an arbitrary horizontal load of $1000 \mathrm{kN}$ was applied at the left end of each horizontal bar (block strip) of the equivalent frames 01 and 02 (Fig. 7-b); (b) the horizontal displacement of the upper knots of each frame was obtained, through the SAP2000; (c) the stiffness of each frame was calculated by the ratio between the force value $(1000 \mathrm{kN})$ and the value of the corresponding displacement, as is exposed in Table 3; (d) a rigid beam (rigid member) was modeled in Ftool to represent the rigid diaphragm (dolphin block), supported on elastic translational supports, as presented in Fig. 8.

These support represent the strips (frames) and their stiffness coefficients are equal to the stiffness determined as per the item (c); (e) the berthing load (901 kN) was applied in the central position of the beam; (f) the reaction of each translational elastic support was obtained in the Ftool program and is displayed in Table 4, where these reactions are the portion of the horizontal load (berthing load) that each frame receives.

Horizontal loads (reactions) shown in Table 4 (obtained by the process described above) and its moments (with lever arm equal to $1.20 \mathrm{~m}$ ), were applied in each equivalent frame, at the left end of each horizontal bar.

Table 3. Stiffness coefficients of the equivalent frames

\begin{tabular}{ccccc}
\hline $\begin{array}{c}\text { Equivalent } \\
\text { frame }\end{array}$ & Matching strips & $\begin{array}{c}\text { Horizontal } \\
\text { force applied } \\
(\mathrm{kN})\end{array}$ & $\begin{array}{c}\text { Displacement } \\
(\mathrm{m})\end{array}$ & $\begin{array}{c}\text { Spring } \\
\text { constant } \\
(\mathrm{kN} / \mathrm{m})\end{array}$ \\
\hline 1 & 1 and 4 & 1000 & 0.0488 & 20491.8 \\
2 & 2 and 3 & 1000 & 0.0163 & 61349.7 \\
\hline
\end{tabular}

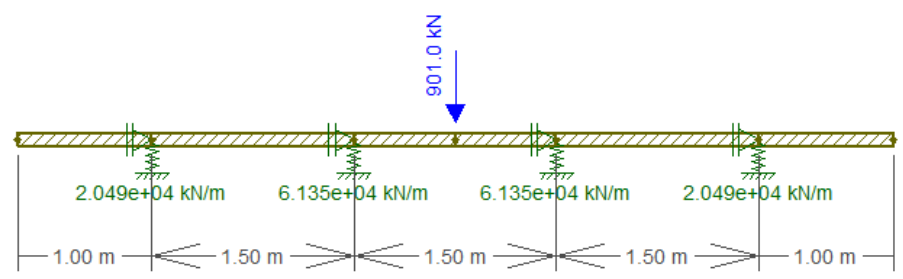

Fig. 8 Rigid beam (Rigid Member) in the Ftool program

Table 4. Rigid beam reactions

\begin{tabular}{ccc}
\hline Equivalent frame & Matching strips & Support Reaction $(\mathrm{kN})$ \\
\hline 1 & 1 and 4 & 112.8 \\
2 & 2 and 3 & 337.7 \\
\hline
\end{tabular}




\subsection{Loads Combination}

According to NBR-6118[2], the last normal combinations of this work, shown in Table 5, can be expressed, both for vertical and horizontal loads, by:

$$
\boldsymbol{F}_{\boldsymbol{d}}=\boldsymbol{\gamma}_{g} \cdot \boldsymbol{F}_{g, k}+\gamma_{q}\left(\boldsymbol{F}_{q 1, k}+\boldsymbol{\psi}_{\mathbf{0}} \boldsymbol{F}_{q 2, \boldsymbol{k}}\right)
$$

The weighting coefficients of the actions in the Ultimate Limit State and the reduction coefficients of the variable loads adopted were, respectively: $\gamma g=1.4 ; \gamma q=1.4$ and $\psi 0=0.6$.

Table 5. Loads combinations

\begin{tabular}{cccc}
\hline Combination & Permanent load & Main variable load & $\begin{array}{c}\text { Secondary variable } \\
\text { load }\end{array}$ \\
\hline 1 & Deadweight & Berthing load & Live load \\
2 & Deadweight & Live load & Berthing load \\
\hline
\end{tabular}

\section{Results and Discussions}

In relative terms, the finite element model with the use of plate elements is closest to the actual structure, followed by the grid model and finally, the equivalent frame models. The values of the normal compression forces and bending moments along the lines of piles tend to be smaller in the first method and grow as the structure is simplified. It is possible to observe in Fig. 9 for the normal compression force and Fig. 10 for the bending moment.

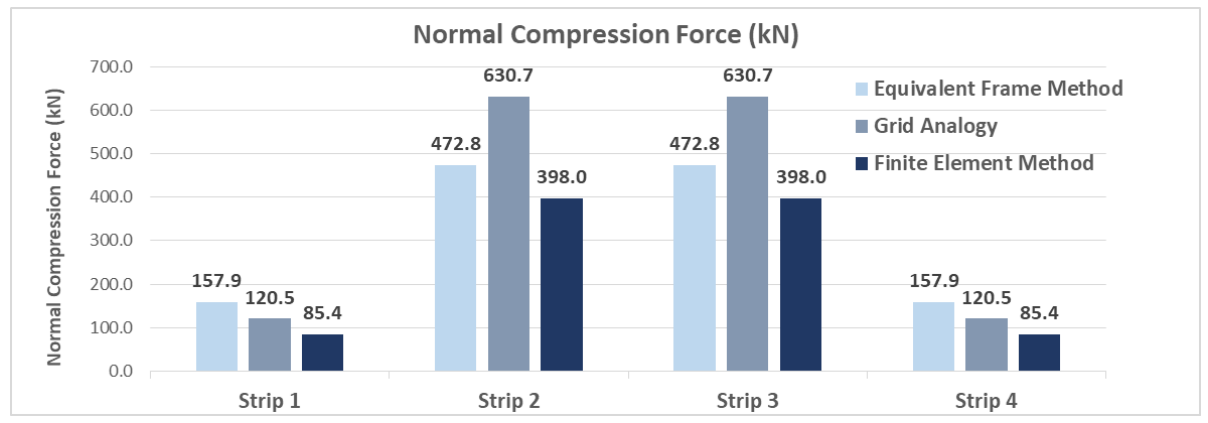

Fig. 9 Normal compression force in the dolphin block

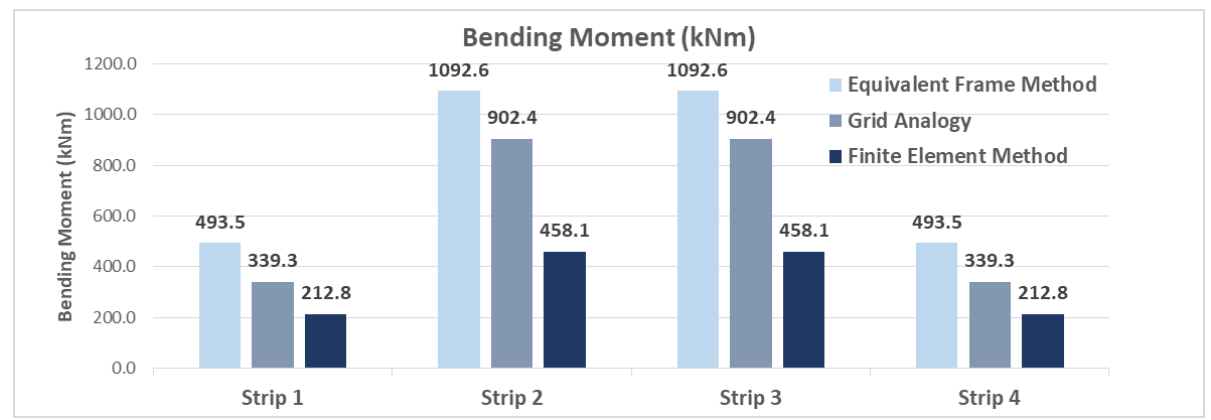

Fig. 10 Bending moment in the dolphin block

Observing Fig. 9 and Fig. 10, it is noted that the finite element model offered the lowest values for both internal forces: normal compression force and bending moment, along the 
lines of piles. This occurs due to the presence of the plate element that gives a greater absorption and, simultaneously, the distribution of these internal forces.

The normal compression force is mostly resulting from the horizontal berthing load. It is noted in Fig. 9 that for strips 2 and 3 the grid model exceeded the normal compression force values of the equivalent frame models. This is due to the application of the berthing load, in the grid model, directly at the ends of the bars, which represent strips 2 and 3 , thus generating a normal force of $1.4 \times \mathbf{4 5 0 . 5}=\mathbf{6 3 0 . 7} \mathbf{~} \mathbf{N}$ in these strips. On the other hand, the equivalent frames received a portion of the berthing load proportional to its stiffness. Therefore, the force is distributed between the four block's strips, which results in a normal compression force value less than the resulting from the grid model. Still, the two simplified models overestimated the values resulting from the finite element model, going according to the trend.

The bending moments resulting from the three methods followed the expected: higher bending moment values for the simplest model - equivalent frame models, decreasing to the grid model and containing the smallest values for the most robust model- finite element model.

\section{Conclusion}

It is notorious that the design of a breasting dolphin through the Equivalent Frame Method or even through of the Grid Analogy is a conservative one. However, using a program that solves structures by the stiffness method it is possible to design the structure with greater speed, simplicity and satisfying the security levels. In particular, the Equivalent Frame Method showed up be suitable for this type of structure, because it follows the tendency to overestimate the values of the grid model, except for the central strips, which still overestimates the values given by the Finite Element Method. Therefore, it is possible to conclude that this method can be employed for a pre-design of a breasting dolphin block or a conservative design that satisfies the security levels.

\section{References}

[1] Araújo JM. Curso de concreto armado (4 ed., Vol. 3). Rio Grande: Dunas, 2014.

[2] Associação Brasileira de Normas Técnicas. NBR 6118: Projeto de estruturas de concreto - procedimento. Rio de Janeiro: ABNT, 2014.

[3] Computers and Structures, Inc. CSI Analysis Reference Manual - SAP2000 Advanced 14.2.2. University Avenue: Berkeley, 2010.

[4] Fentek. Marine Fendering Systems. Hamburg: Fentek, 2008.

[5] Martha LF. Ftool - Um programa gráfico-interativo para ensino de comportamento de estruturas. Rio de Janeiro: Tecgraf/PUC- Rio, 2018.

[6] Mason J. Obras portuárias. Rio de Janeiro: Campus, 1981.

[7] PIANC (International Navigation Association). Guidelines for the Design of Fender System. Report of Working Group 33. Bruxelas: PIANC, 2014.

[8] Tsinker GP. Port Engineering - Planning, Construction, Maintenance, and Security. Hoboken: John Wiley \& Sons, Inc, Michigan, 2004.

[9] Vaz LE. Método dos Elementos Finitos em análise de estruturas. Rio de Janeiro: Elsevier, 2011. 